\title{
La pintura de mi pueblo: un arte dialogante y crítico
}

\section{Brus Rubio Churay}

\section{(2) OpenEdition}

1 Journals

Edición electrónica

URL: https://journals.openedition.org/jsa/19488

DOI: $10.4000 /$ jsa. 19488

ISSN: 1957-7842

Editor

Société des américanistes

\section{Edición impresa}

Fecha de publicación: 30 septiembre 2021

Paginación: 103-110

ISSN: 0037-9174

\section{Referencia electrónica}

Brus Rubio Churay, «La pintura de mi pueblo: un arte dialogante y crítico», Journal de la Société des américanistes [En línea], 107-1 | 2021, Publicado el 30 septiembre 2021, consultado el 02 septiembre 2022. URL: http://journals. openedition.org/jsa/19488 ; DOI: https://doi.org/10.4000/jsa. 19488 


\title{
La pintura de mi pueblo: un arte dialogante y crítico
}

\author{
Brus Rubio Churay
}

\begin{abstract}
Este texto resulta de una entrevista al pintor murui-muina Brus Rubio Churay (clan Ziueni), realizada y editada por Óscar Iván García. Es un comentario al artículo "Représenter avec le rite: réflexivité et danse rituelle dans un tableau muruimuina" (Representando con el rito: Reflexividad y danza ritual en una pintura murui-muina) escrito por Óscar Iván García para este número del Journal de la Société des américanistes. Se trata, por un lado, de las opiniones del artista sobre los análisis del antropólogo y, por el otro, de una manera de señalar los elementos necesarios para entender su obra. Como en el caso de sus pinturas, es un documento que invita a reflexionar sobre las formas en que concebimos el diálogo entre mundo indígena y mundo occidental; entre arte contemporáneo y arte indígena; entre antropología y tradición; y entre identidad y modernidad.
\end{abstract}

\section{Diálogo intercultural}

La pintura La invitación y llegada con fuerza, a la que se refiere el artículo de Óscar Iván García, es un cuadro en el que se representan personas rodeadas de paisajes amazónicos: se trata de evocaciones de plantas importantes para la sociedad murui-muina. En el cuadro he querido mezclar estos paisajes con un único elemento Occidental: la Plaza Mayor frente al Palacio de gobierno peruano. En el lienzo aparecen mujeres y personas occidentales con las que represento a la gente que aprecia la Amazonia. Se trata de una escena en la que las personas están llegando a una fiesta; es la ceremonia del "pedido de frutas" que realizamos en algunos de nuestros bailes rituales. Esta ceremonia es una manera de agradecer la abundancia que nos da la tierra. En este rito el celebrante comparte su producción con otros pueblos. Es una invitación a escuchar las canciones que traen los invitados. Es una ceremonia en la que el dueño de la fiesta se alimenta de la sabiduría de sus invitados, mientras que los jóvenes que participan aprenden, bailan, encuentran nuevas amistades y crean sus familias. 
Este cuadro es un llamado de atención al gobierno para que reconozca nuestra forma de ser, para que nos trate como una cultura con sabiduría, que tiene sus propias prácticas, su forma de ser. Es un llamado a la sociedad para que, sin quitarnos nuestras potencialidades, nos vea como la esperanza de una nación. Expresar esto a través de un cuadro resulta una forma eficaz de sensibilizar. Es una estrategia para llegar a los círculos de poder de Occidente, donde con frecuencia nuestras iniciativas se ven bloqueadas por las barreras burocráticas que nosotros llamamos "papeleos". En este sentido, el arte tiene la ventaja de generar llamados que reconocen a los individuos, sin mirar la institucionalidad, sino más bien concentrándose en las personas, en la humanidad. Así, el arte logra movilizar nuestras demandas de una manera orgánica a través de nuestra alegría y de nuestra cultura.

\section{Visión indígena y arte crítico}

Actualmente pocos pintores en la Amazonia producen una forma de arte "crítico" como el de mis cuadros. Es decir, una crítica en la que dialogan la visión indígena y la visión occidental. Realizar este tipo de obra exige una "transmutación". Esto significa, por un lado, cortar las alineaciones con la tradición occidental para verse a sí mismos como indígenas y, por el otro, reconocer la pintura como un tipo de arte "dialogante". Es decir, es un tipo de arte que trata elementos occidentales poniéndolos cerca de nuestro imaginario cultural sin que por ello se pierdan nuestros elementos identitarios.

Este proceso de diálogo y de desalienación del que hablo no es nuevo para mí: deriva de mi propia historia de vida. Recordemos que yo vengo de dos pueblos: mi padre es Murui-Muina, mal llamado Uitoto, y mi madre es Bora. Es decir, desde mi infancia he tenido que comprender lo que significa el diálogo y la desalienación entre culturas. Esta transmutación de la mirada no es fácil, porque se trata, por un lado, de generar una propuesta artística en la que tomamos distancia de la influencia occidental sin por tanto rechazarla; y por el otro, de un proyecto en el que exploramos lo tradicional sin reducirnos a ello. Es un proceso que nos obliga a interrogarnos sobre nosotros mismos. Una reflexión que nos lleva a disentir de las opiniones de las personas que defienden la inmutabilidad de nuestras tradiciones, tanto como de aquellas que afirman que nuestras culturas no tienen otra opción que el cambio y la asimilación a la modernidad.

Esta idea de diálogo y transmutación no es nueva en mi obra. Como se describe en el artículo, en el cuadro La invitación y llegada con fuerza describo un diálogo entre el mundo indígena y el estado peruano, pero es un tema que ya había tratado en 2013-2014 en otros cuadros como Pasaporte amazónico, en el que se recrea la escena entre el río Ampiyacu (Perú) y la Torre Eiffel de fondo, con la sociedad francesa como interlocutora. Del mismo modo, en el cuadro Invitación a la fiesta Smithsonian (2015) muestro este diálogo, pero 
allí el interlocutor es la sociedad estadunidense y la escena es recreada entre el Puente Inca de Q'eswachaka y el Capitol Building. De más recientemente factura es el cuadro Tate Britain (2020), en el que el interlocutor es la sociedad británica y cuyo telón de fondo es el museo que lleva ese nombre. Todas estas pinturas siguen el mismo modelo. Se trata de variaciones de una escena ritual en las que cambia el interlocutor no-indígena. En estas obras el objetivo es señalar la tensión entre el mundo indígena y el mundo occidental desde una perspectiva doblemente crítica: por un lado, porque rechazamos la inmutabilidad de la tradición y por el otro porque resistimos la influencia de Occidente en el mundo indígena.

Otros artistas amazónicos han trabajado el tema del ritual con objetivos similares, como por ejemplo los pintores del "arte visionario" que usan la ayahuasca. Este es un movimiento en el que las obras pueden ser bastante críticas. Es un tipo de arte que me resulta bastante autóctono, y que es muy frecuente entre los

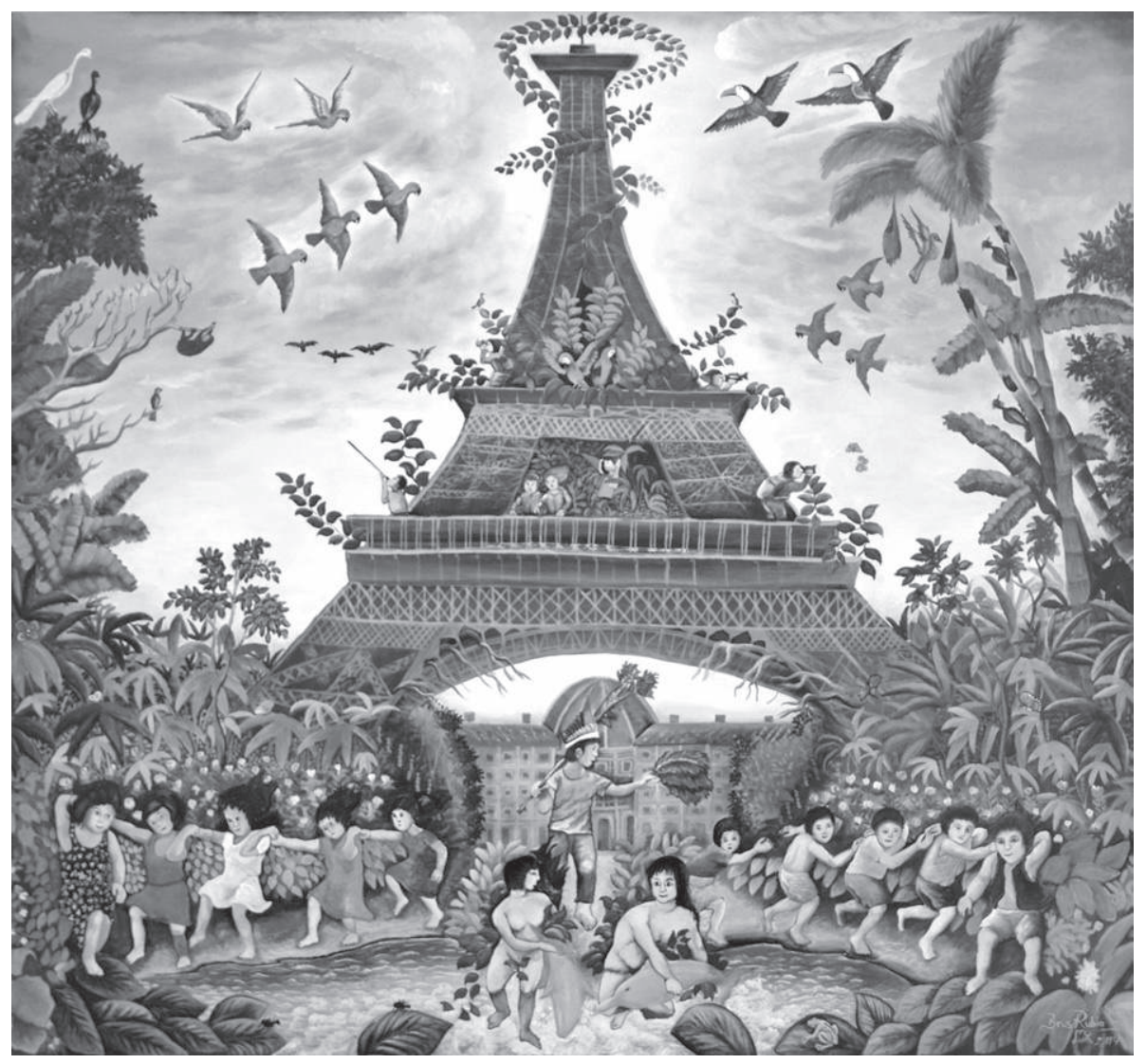

Fig. 1 - Pasaporte amazónico 2 (B. Rubio, 2014) 
artistas contemporáneos de la región. Estos artistas contribuyen al arte amazónico usando formas y estilos diferentes. No obstante, no es una generalidad. Otros artistas amazónicos representan el ritual limitándose a evocar los aspectos mágicos que lo caracterizan. Su objetivo es poner de relieve el lado misterioso y selvático de las tradiciones amazónicas, pero sus obras no generan ningún tipo de reflexión sobre la manera de ser indígena en el mundo contemporáneo.

\section{Antropología y tradición}

En su artículo Óscar Iván García ha hecho una interpretación de mi trabajo desde el punto de vista académico. Pienso que él ha buscado revelar la profundidad que existe detrás de cada imagen. Se trata de la mirada de un intelectual que al mismo tiempo trata de entender y de hacer entender estos significados en otros espacios sociales. En ese sentido su contribución es muy valiosa. Pienso también que es un trabajo exigente pues para lograr esto se necesita de mucha investigación, es preciso preguntarse: ¿por qué estas pinturas?, ¿por qué sus formas?, ¿cuáles son sus significados?, etc. Un elemento que llama la atención de este artículo es que, a mi parecer, muestra los símbolos y la estructura social de mi cultura, que se han debilitado desde hace ya un buen tiempo. En ese sentido creo que el documento contribuye a la valoración de una fiesta ritual que es parte de la tradición de un pueblo.

En efecto, el artículo llama la atención sobre el papel del ritual en el diálogo entre mundo indígena y mundo occidental del que he hablado anteriormente. No obstante, algo que ha escapado al análisis de Óscar Iván García es la manera en que mi trabajo busca evocar el conocimiento indígena. En el caso de La invitación y llegada con fuerza lo he señalado de varias formas, pero sobre todo a través de la huella del jaguar que he pintado en la parte inferior derecha en color naranja. Esta huella, orientada en dirección al observador, significa que los indígenas pasamos por ese lugar. Es una manera de representar nuestro conocimiento, nuestra sabiduría. Es una forma de decir que nuestro saber es algo que debe respetarse. Es decir, por allí puedes pasar, pero nos tienes que reconocer y respetar... Desde mi punto de vista eso es identidad, eso es lo que somos. Es una forma de hacer ver la fortaleza de mi tradición, algo que no se cuenta en la parte académica ni tampoco en los círculos artísticos.

El artículo de este autor me hace pensar en otros de sus colegas que han trabajado en mi comunidad. Ellos hablan bastante de rescatar las lenguas, de hacer las prácticas tradicionales: las cocameras (polvo de coca), el ampiri (pasta de tabaco), etc. Sin embargo, algunos de nuestros jóvenes indígenas a veces no saben por qué todavía hoy tenemos que seguir practicando estas tradiciones. Tenemos la impresión de que debemos comportarnos como occidentales para ser aceptados. Y es allí donde siento que es importante el trabajo de los antropólogos: 


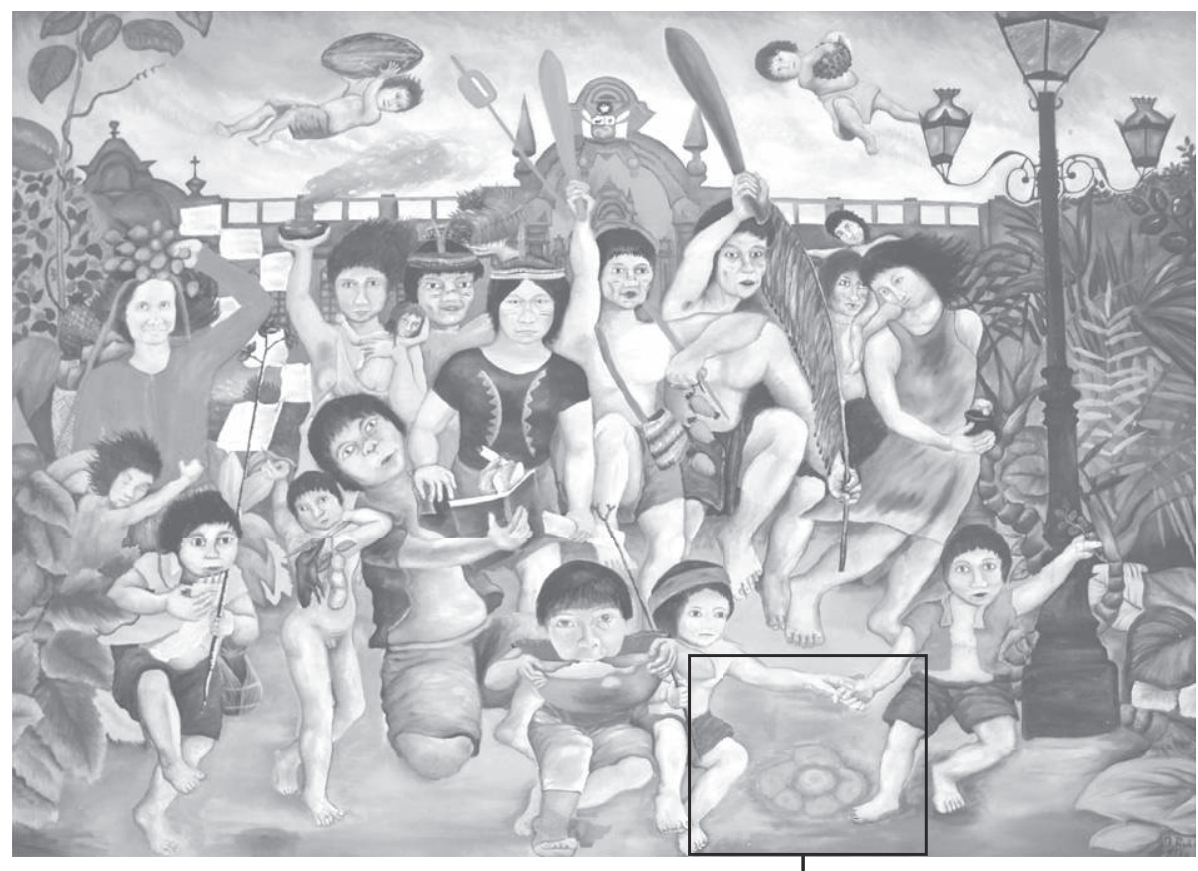

Fig. 2 - La huella del jaguar, detalle de La invitación y llegada con fuerza (B. Rubio, 2014)

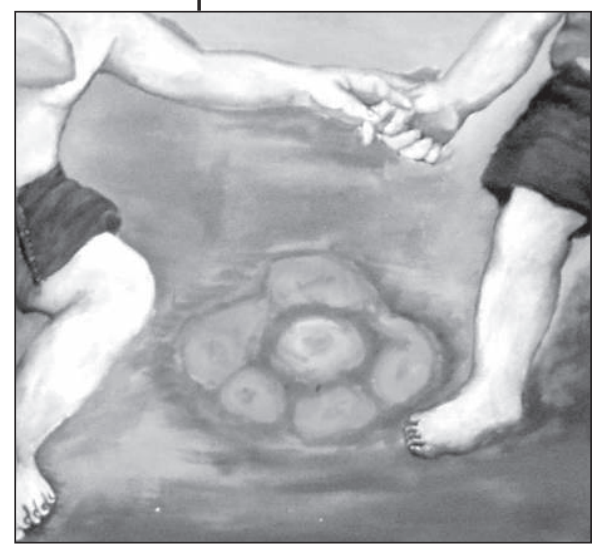

con sus investigaciones ellos nos muestran por qué es necesario continuar con nuestras usanzas. Aun si con frecuencia nosotros no sabemos la razón por la cual el antropólogo viene a nuestra comunidad. Es decir, en muchas ocasiones ignoramos por qué hacen lo que hacen, pero, con el tiempo, hemos podido ver que la antropología puede mostrar esa parte social que motiva a los jóvenes a expresar su identidad.

Pero no basta con motivar. El joven indígena escucha las palabras del antropólogo que lo invita a conservar su identidad y su lengua, pero no puede dejar 
de ver su realidad y sus necesidades. El joven sabe que, a pesar de lo dicho por el antropólogo, tiene que trabajar para ganar dinero y sostener a su familia. El joven indígena no tiene otra opción, él debe preguntarse cómo ganar el pan sin perder su identidad y eso en ocasiones se traduce en ganar el alimento a través de su identidad, como en esos proyectos etnoturísticos que son cada vez más frecuentes en la Amazonia. Porque revalorar nuestra identidad no solamente es política, ni hace honor a la vida ancestral, sino que es un hecho de la realidad. La dificultad consiste entonces en saber cómo fusionar la revaloración de nuestra identidad con las acciones que nos ayudan a resolver las necesidades de la vida diaria.

Entiendo que los antropólogos dan las herramientas para empezar esta tarea de dialogar y preservar la identidad, por ejemplo recuerdo a Jürg Gasche (19402020), un antropólogo que contribuyó bastante al conocimiento de nuestro pueblo. Él quiso ser bastante claro conmigo. Él me aconsejaba valorar la identidad con una apreciación crítica, porque ya estamos en otro tiempo. Él decía que, si valoramos nuestra identidad sin apreciación crítica, estamos viendo un solo lado de la realidad. Mi experiencia con los antropólogos me muestra entonces que el trabajo de estos científicos puede otorgarnos cierto acercamiento a nuestra situación actual, que nos permite caminar y tener una posición de autoestima cultural. Se trata de un tipo de investigación que nos muestra la necesidad del empoderamiento como persona... sin miedo.

\section{Arte indígena e influencias artísticas}

Mi trabajo es con frecuencia clasificado como "arte indígena". Esa clasificación en principio no me incomoda. Sin embargo, a veces tengo la impresión de que "arte indígena" es una categoría que se aprovecha del adjetivo "indígena". Un término que, desde mi punto de vista, sigue evocando la noción de "indio" que no parece lograr quitarse su carga peyorativa. Es decir, al reemplazar el término "indio" por el eufemismo "indígena", seguimos señalando el contraste entre civilización y salvajismo. Junto a ello, tengo la impresión de que el término "arte indígena" es usado para referirse a un tipo de arte, pero sin describir las características de las obras: es una categoría que parece contentarse con señalar únicamente el origen autóctono de los artistas. No obstante, en el interior de lo que se llama arte indígena hay una variedad de artistas y de "escuelas" diferentes como la de Pucaurquillo.

Como otros artistas amazónicos, me pregunto si por tratarse de pintores indígenas nuestro trabajo debe ser desvinculado de nociones como la de arte contemporáneo. Me pregunto también si mi trabajo como artista individual debería siempre quedar oculto bajo la categoría de arte indígena... a veces también me pregunto si un día mi obra podrá ser reconocida no como arte indígena sino como "arte de Brus Rubio". Pero eso no es así, tal vez porque 
he sido conocido a través del arte de mi pueblo... de las fiestas ancestrales. No obstante, yo pienso que eso debería ser objeto de un debate, porque como otras corrientes artísticas, el arte indígena es una forma de reconocer el trabajo del artista no solo como integrante de una corriente sino también como individuo.

Creo igualmente que es preciso reconocer que los artistas amazónicos no dialogan solamente con los artistas indígenas. Muchos de ellos participan de exposiciones en el extranjero y están en contacto con el arte de otras regiones del mundo. A mí en particular me llaman la atención varios pintores europeos. Me gusta, por ejemplo, el arte de Pierre Paul Rubens (1577-1640) por sus paisajes y porque en sus cuadros hay un lado humano. De Rubens también me llama la atención la manera en que representa el movimiento del cuerpo y la manera en que usa los colores porque me parece que tienen mucha fuerza. También me gustan los pintores del dadaísmo por su manera de ver la cultura. Tengo la impresión de que para los dadaístas la cultura debe ser transformada y por eso pienso que en estos cuadros las figuras están deformadas. Otro pintor que me llama mucho la atención es Leonardo Da Vinci (1452-1519). Yo he visto las formas de sus personajes, y aunque es un arte bastante religioso, me llama la atención la manera en que compone sus cuadros y su forma de representar el movimiento humano.

Lo anterior para mí es importante porque aquí en la Amazonia también hay mucho movimiento humano, que se manifiesta por ejemplo en las danzas. El movimiento también se manifiesta en las aves, las serpientes... es un movimiento que incluso forma parte de la mitología. Es por eso que en mis pinturas también el movimiento es tan importante. En el caso de La invitación y llegada con fuerza esto se refleja en los gestos y las danzas de varias de las personas incluidas en el cuadro. Mi forma de representar el movimiento y de usar el color es entonces el resultado de la observación de esos artistas tanto como de mi propia experimentación.

Otro pintor que me llama la atención es Diego Velázquez (1599-1660) quien, como se sabe, pintó Las Meninas (1656). Vi por primera vez ese cuadro cuando era niño. Lo encontré en un pequeño diccionario guardado en la casa de mi padre en mi comunidad. Lo vi en ese diccionario mucho antes de poder contemplarlo en la realidad. Fue muchos años después, cuando pude visitar Madrid, que lo vi personalmente en el museo del Prado. En compañía de un amigo que conoce mucho de arte, fuimos a ese museo. Allí mi amigo me explicó en detalle por qué Las Meninas es un cuadro tan importante. Me llamó la atención que hay un misterio en el cuadro, pues no es claro a quién se está pintando. El artista se está representado allí delante de un lienzo, colocándolo de espaldas, sobre un caballete rústico. Y al observar mejor la escena llega un momento en que quien está parado delante del cuadro no sabe si lo están pintando a él o si pintan a alguien más. A mí me gusta que, para Velázquez, el público sea parte de su imaginario, el público es parte de su cuadro, es parte de su tiempo. 
Como en la obra de Velázquez, en La invitación y llegada con fuerza el público tiene otra manera de implicarse con el cuadro. Cuando lo he pintado, no he querido pintar la Maloca (casa tradicional), sino que he pintado a la gente que está llegando a ella. Pero esa gente, ¿a dónde llega? Pueden estar llegando a muchas partes, en función del lugar en el que se lo exponga, en función de la mirada de cada observador... Por eso creo que La invitación y llegada con fuerza siempre va a ir a todas partes del mundo.

\section{A manera de conclusión}

Finalmente permítanme decir que estoy muy contento de poder compartir con los lectores de este número del Journal de la Société des américanistes. Me anima pensar que podrán entender mejor mi trabajo, que no es otra cosa que el resultado de una formación con mis padres y abuelos. Me alegra saber que podrán disfrutar de esta obra y que podrán verla como un mensaje de esperanza. Me reconforta saber que a través de mi trabajo podrán saber que en la Amazonia hay muchos otros artistas con mucho talento y que, como yo, pueden contarles de una manera diferente nuestro modo de pensar. Invito a mis colegas pintores de la Amazonia a que sigan explotando sus posibilidades, sus lenguajes, sus materiales, para comunicar lo que somos; porque de esa manera abrimos otra posibilidad a la sobrevivencia de nuestros saberes y lenguajes ancestrales. Invito también a la gente de mi comunidad y a los demás indígenas de la Amazonia a que tratemos de conocer nuestras transformaciones, para aceptar nuestras carencias, pero también para superarlas y prevalecer. Termino invitando especialmente a los niños indígenas a que, al mirar sus chacras, sus ríos, sus árboles, sus frutas, vean que allí es donde reposa nuestra alegría. Los invito a pensar en que pintar toda esa alegría es también una manera de preservar todo lo que somos. 